\title{
Spinal Dural AVFs: Classifications and Advanced Imaging
}

\author{
Michihiro Tanaka
}

\section{Abbreviations}

\begin{tabular}{|c|c|}
\hline ASA & Anterior spinal artery \\
\hline CBCT & $\begin{array}{l}\text { High-resolution cone beam computed tomo- } \\
\text { graphy }\end{array}$ \\
\hline CE-MRA & Contrast-enhanced MR angiography \\
\hline DSB & Dorsal somatic branch \\
\hline DV & Initial segment of the draining vein \\
\hline MRI & Magnetic resonance imaging \\
\hline PSA & Posterior spinal artery \\
\hline SDAVFs & Spinal dural arteriovenous fistulas \\
\hline SEAVFs & Spinal epidural arteriovenous fistulas \\
\hline
\end{tabular}

\section{Introduction}

Spinal dural arteriovenous fistulas (SDAVFs) are the most common spinal vascular malformation. The clinical symptoms, however, are usually nonspecific. Therefore, the neurosurgeon or neuroradiologist is often the first clinician to make the initial diagnosis based on MR imaging, with differential diagnoses causing confusion [1-4]. Recent imaging technology can visualize the detailed angioarchitecture of SDAVFs at the level of the shunt point. We retrospectively analyzed 22 consecutive cases of SDAVFs and identified the shunt point and the related vasculatures of SDAVFs based on the MRI, CE-MRA, high-resolution cone beam CT (CBCT), spinal angiography, and 3D-CT. The efficacy and sensitivity of these imaging modalities were assessed, and a new concept of classification of SDAVFs was introduced in terms of the anatomical point of view.

M. Tanaka $(\bowtie)$

Department of Neuroendovascular Surgery, Kameda Medical Center, Kamogawa City, Chiba, Japan http://www.kameda.com/us/medi_services/staffs/details_ 34_175.html

\section{Materials and Methods}

From 2005 to 2017, 22 consecutive cases of SDAVFs were diagnosed with MRI and angiography. Spinal epidural arteriovenous fistulas (SEAVFs) located at the lumbar spine were excluded from this study. Our population was composed of 21 men and one woman. The mean patient age was $67 \pm 12.4$ years (range 42-79 years). High-resolution cone beam CT (CBCT) was introduced in 2013 in our institute, and a total of 11 cases received CBCT. The visualization of anterior spinal artery (ASA), posterior spinal artery (PSA), dorsal somatic branch (DSB), and the primary foot of the draining vein (DV) were confirmed. If transarterial embolization was indicated, superselective angiography from the dominant feeder was referred to in order to confirm the precise topographical location of the shunt point. A total of 18 cases were treated with superselective transarterial embolization with Histoacryl glue. The other four cases were treated by surgical clipping of the arterialized bridging vein after laminectomy.

\section{MR Imaging and Contrast-Enhanced MR-DSA}

All 22 patients underwent extensive spinal MR-DSA with gadolinium contrast and MR imaging (1.5 T and/or $3 \mathrm{~T})$. The extension of the $\mathrm{T} 2$ signal hyperintensity and the medullary contrast enhancement was qualified by the number of vertebral levels shown to be affected on T1 and T2 MR images. The appearance of the perimedullary veins was rated subjectively as absent or prominent due to their tortuous and dilated appearance in the T1 and T2 images. Contrast-enhanced MR angiography (CE-MRA) is similar to contrast-enhanced CT angiography, except a gadolinium-based agent (instead of an iodine compound) is injected. Just as iodine produces X-ray attenuation allowing visualization of vessels on CTA, gadolinium shortens the $\mathrm{T} 1$ of blood, rendering vessels bright on CE-MRA (Fig. 1). 
Fig. 1 (a) T1-weighted image on sagittal view showed the swelling of spinal cord with the appearance of central myelopathy. (b) CE-MRA depicted the shunt point at the level of midthoracic spine. This modality enabled effective

identification of the level of the shunt point
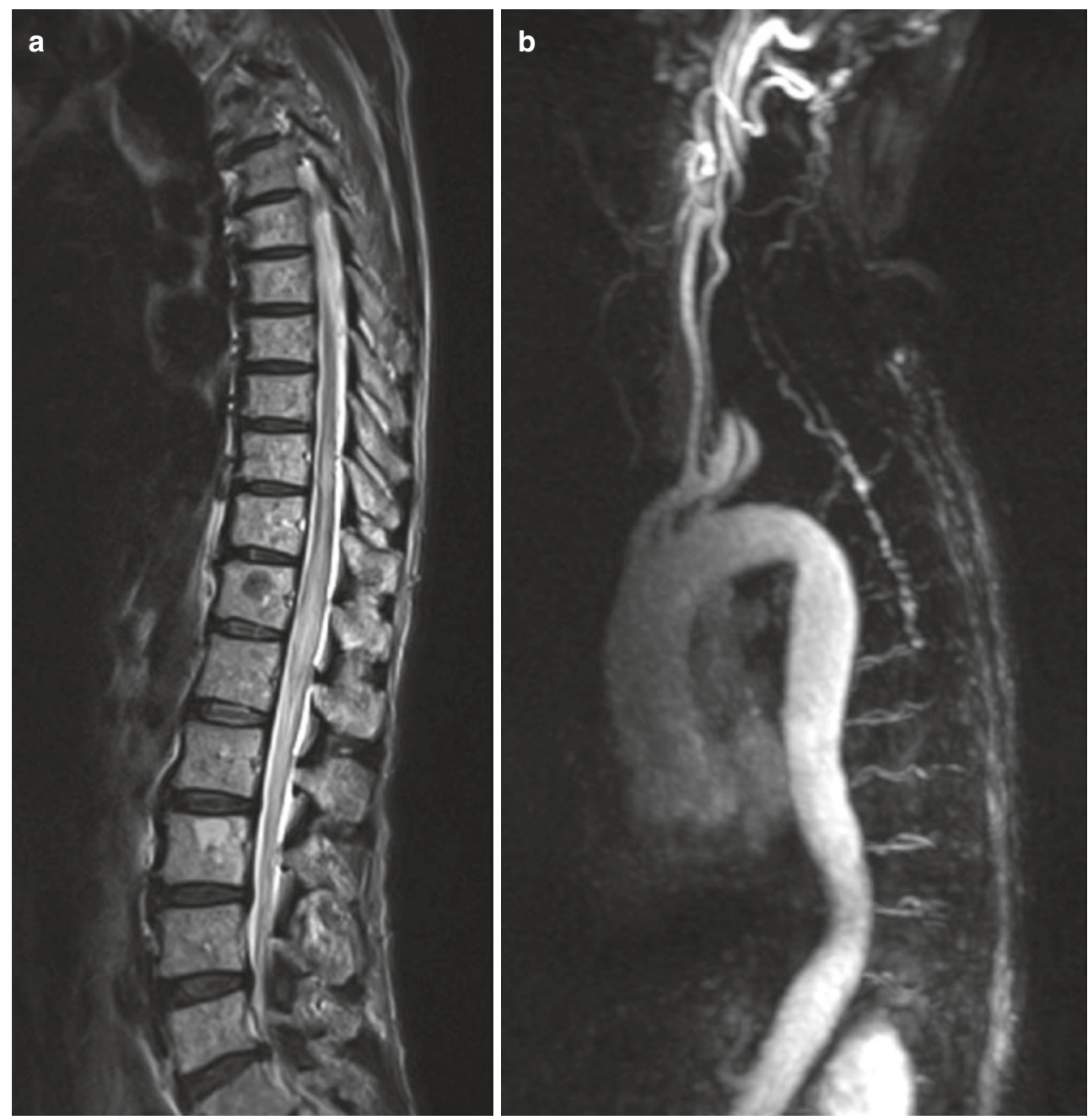

\section{D-CT}

The introduction of multi-detector row computed tomography (MDCT) has allowed further refinements in detecting microstructures in the spinal cord region. MDCT was performed with a commercially available MDCT scanner (Aquilion ONETM/GENESIS Toshiba Medical Systems, Tokyo, Japan) with a gantry rotation speed of $0.35 \mathrm{~s}$ and a detector configuration of $32.0 \times 1.0 \mathrm{~mm}$; the moving speed of the table was $27 \mathrm{~mm} / \mathrm{s}$. All scans were acquired in a cephalocaudal direction. Patients underwent MDCT followed by arterial and venous phases. Patients received $100 \mathrm{~mL}$ of iomeprol (Iomeron, $350 \mathrm{mg} / \mathrm{mL}$, Bracco-Eisai, Otsuka, Japan) with a monophasic injection technique by means of a power injector. Analysis of the three-dimensional (3D) data set for the region of interest in all subjects was also done by experienced radiological technicians using a commercially available workstation (ZIOSOFT, ZIOSOFT Inc., Tokyo, Japan). With ZIOSOFT, 3D reconstruction images of the shunt point and the artery of Adamkiewicz were created using CT images of the arterial phase with a slice thickness of $0.5 \mathrm{~mm}$, manually removing adjacent structures such as vertebral bony structures and the outside of the spinal canal.

\section{DSA and High-Resolution CBCT}

Digital subtraction angiography (DSA) was performed with a femoral approach in a dedicated biplanar neuroangiographic suite. The equipped DSA machine was a flat-panel detector biplane angiography unit (Allura Clarity FD20/20; Philips Medical Systems). Spinal angiography was performed using the standard angiographic technique and investigated total spinal level, including bilateral intercostal artery and adjacent level of the shunt point. Standardized angiography included selective manual injections of $4-5 \mathrm{~mL}$ of $300 \mathrm{mg} / \mathrm{mL}$ of iodinated nonionic contrast medium into the lumbar and intercostal arteries using a 4 or 5 French in the outer diameter of the catheter designed for the spinal angiography. Furthermore, injections into both vertebral arteries, the costocervical arteries, the thyrocervical trunks, and the arterial feeders of the sacral region were added. Once the 
shunt point and the Adamkiewicz artery were identified, the high-resolution CBCT was performed in each corresponding artery after the complete set of the entire spinal angiography. High-resolution CBCT was based on motorized rotational angiography acquisition. The shunt lesion and the region of interest were positioned in the system isocenter around which the C-arm takes a circular trajectory of $220^{\circ}$. The motorized frontal $\mathrm{C}$-arm was used to acquire 30 projection images/s at $80 \mathrm{kV}$, the scanning time was $20 \mathrm{~s}$, and the detector format used was $22 \mathrm{~cm} \times 22 \mathrm{~cm}$. All procedures and acquisitions were performed under general anesthesia. During this acquisition, the anesthesiologist paused the ventilator for around $20 \mathrm{~s}$ of apnea to avoid motion artifact. The acquisition dataset was transferred to the workstation (Xtra Vision; Philips Medical Systems) for the reconstruction process. All high-resolution CBCT images were reconstructed with $512^{3}$ matrixes centered about the regional shunt point and optimized for the visualization of the ASA, PSA, DSB, and DV. After reconstruction of the three-dimensional volume of interest, anatomical details were evaluated by multiplanar reconstructions with volume rendering and manipulation of the parameters on the maximum intensity projection mode.

\section{Results}

The shunt points were well identified on the DSA and CBCT with $100 \%$ of sensitivity, while MRI and MR-DSA showed the shunt points in only $9 \%$ of the cases. 3D-CT showed $18 \%$ of sensitivity (Table 1).

ASA was well-visualized on DSA and CBCT with $100 \%$ of sensitivity; however, MRI and 3D-CT could depict ASA with less than $60 \%$ of the cases (Figs. 1 and 2).

The sensitivity of CBCT was so remarkable that it successfully showed the exact location of the shunt point, ASA, and DV in $100 \%$ of the cases (Fig. 3), but was less able to visualize DSB. According to the analysis of the serial axial and coronal images based on the slab maximum intensity projection (Slab MIP), the exact shunt point in most of the cases was located on the surface of the nerve sleeves. DSB could also be depicted on this slab MIP mode in $68 \%$ of the cases (Fig. 4). The basket formation of the anastomosis between ASA and bilateral PSA was well visualized on
CBCT (Fig. 5). It is usually difficult to identify the PSA on the conventional DSA; in this series, however, the sensitivity to PSA with CBCT was more than $70 \%$ (Fig. 6).

Meningeal branches of the radiculomeningeal artery were the main feeding arteries in 21 of 22 cases (95.5\%). These feeding arteries ran medially on the surface of the dural sleeve and turned longitudinally along the dura mater of the thecal sac. Then they gathered and joined the single vein on the inner dural surface. In 16 cases (72\%), we observed these longitudinal meningeal feeders and a drainage vein that resembled the horizontal $\mathrm{T}$ sign in an anteroposterior view of angiography as well as in CBCT (Fig. 3a).

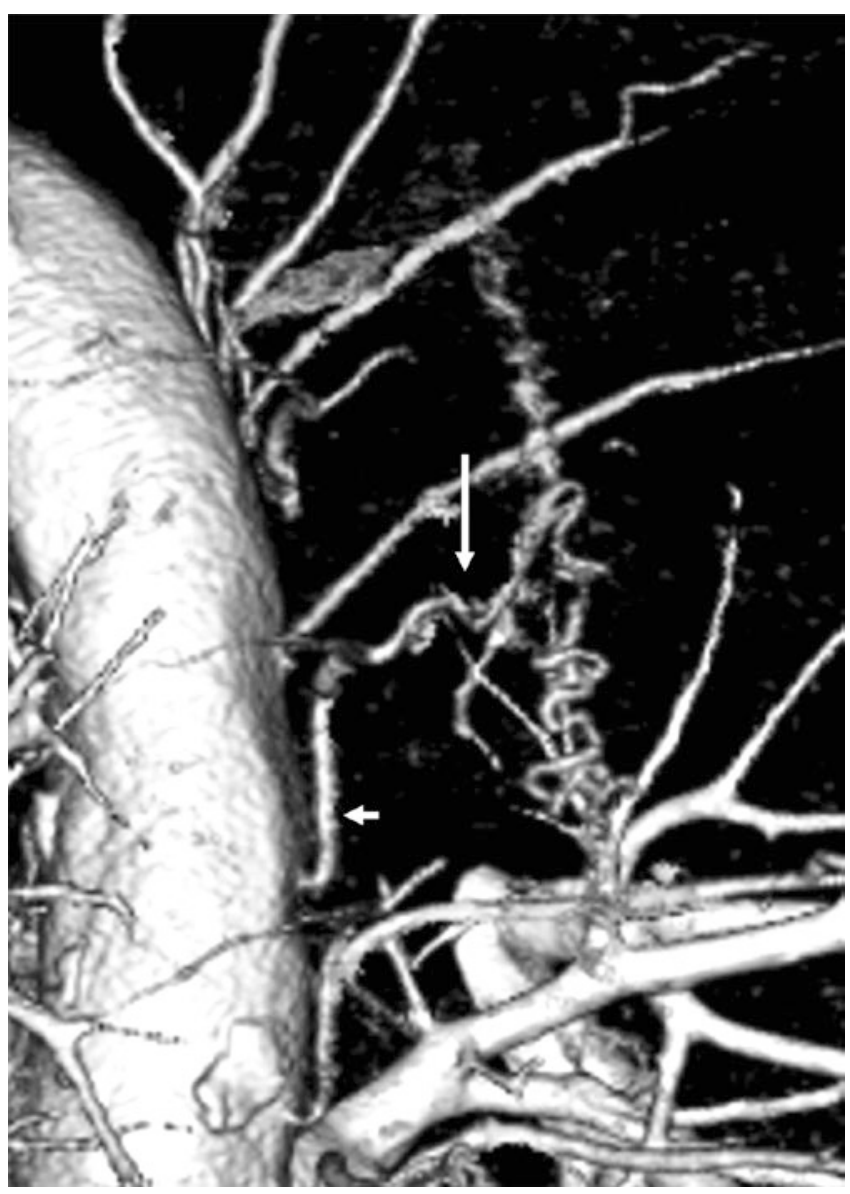

Fig. 2 3D-CT delineated the course of the intercostal artery (short arrow) and the terminal feeder toward the shunt point (long arrow) corresponding to the meningeal branches of the radiculomeningeal artery
Table 1 Visibility of the anatomical structure on each imaging modality associated with SDAVFs

\begin{tabular}{l|c|l|l|l|l}
\hline & MRI & CE-MRA & 3D-CT & DSA & CBCT \\
\hline Shunt point & $2(9 \%)$ & $2(9 \%)$ & $4(18 \%)$ & $22(100 \%)$ & $11(100 \%)$ \\
\hline ASA & $12(55 \%)$ & $13(59 \%)$ & $13(59 \%)$ & $22(100 \%)$ & $11(100 \%)$ \\
\hline PSA & $0(0 \%)$ & $0(0 \%)$ & $1(4.5 \%)$ & $16(73 \%)$ & $8(73 \%)$ \\
\hline DSB & $0(0 \%)$ & $0(0 \%)$ & $0(0 \%)$ & $13(59 \%)$ & $7(64 \%)$ \\
\hline DV & $21(90 \%)$ & $21(90 \%)$ & $18(81 \%)$ & $22(100 \%)$ & $22(100 \%)$ \\
\hline
\end{tabular}

This table shows the number of the prominent and well visible structures on five different radiological images 

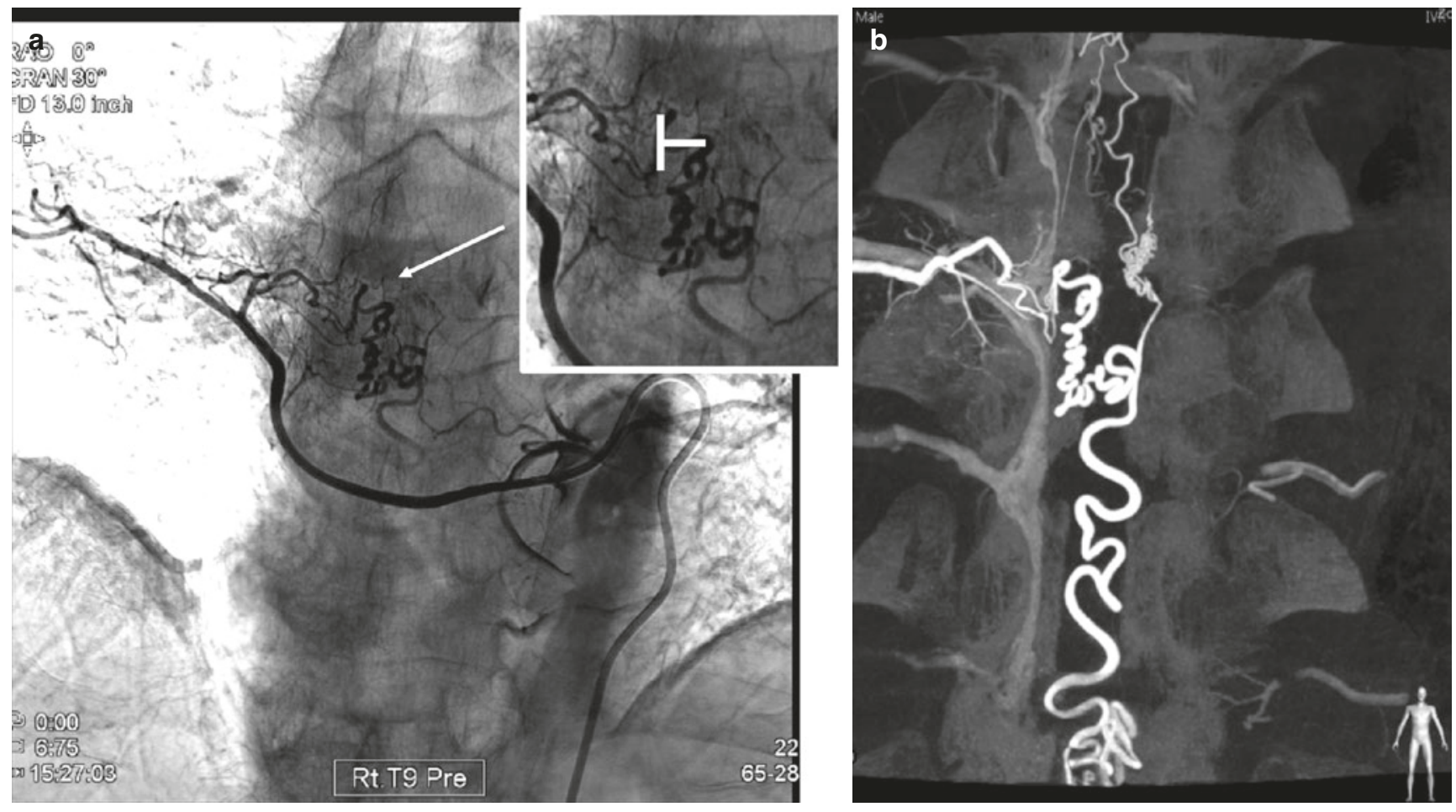

Fig. 3 (a) Conventional DSA injected from the right intercostal artery at the level of T9. It showed the SDAVF with the longitudinal meningeal feeders and a drainage vein. The configuration of this longitudinal meningeal feeder and a drainage vein resembled the horizontal $\mathrm{T}$ sign in an anteroposterior view. (b) CBCT depicted the shunt point, precisely locating it on the lateral surface of the dura mater
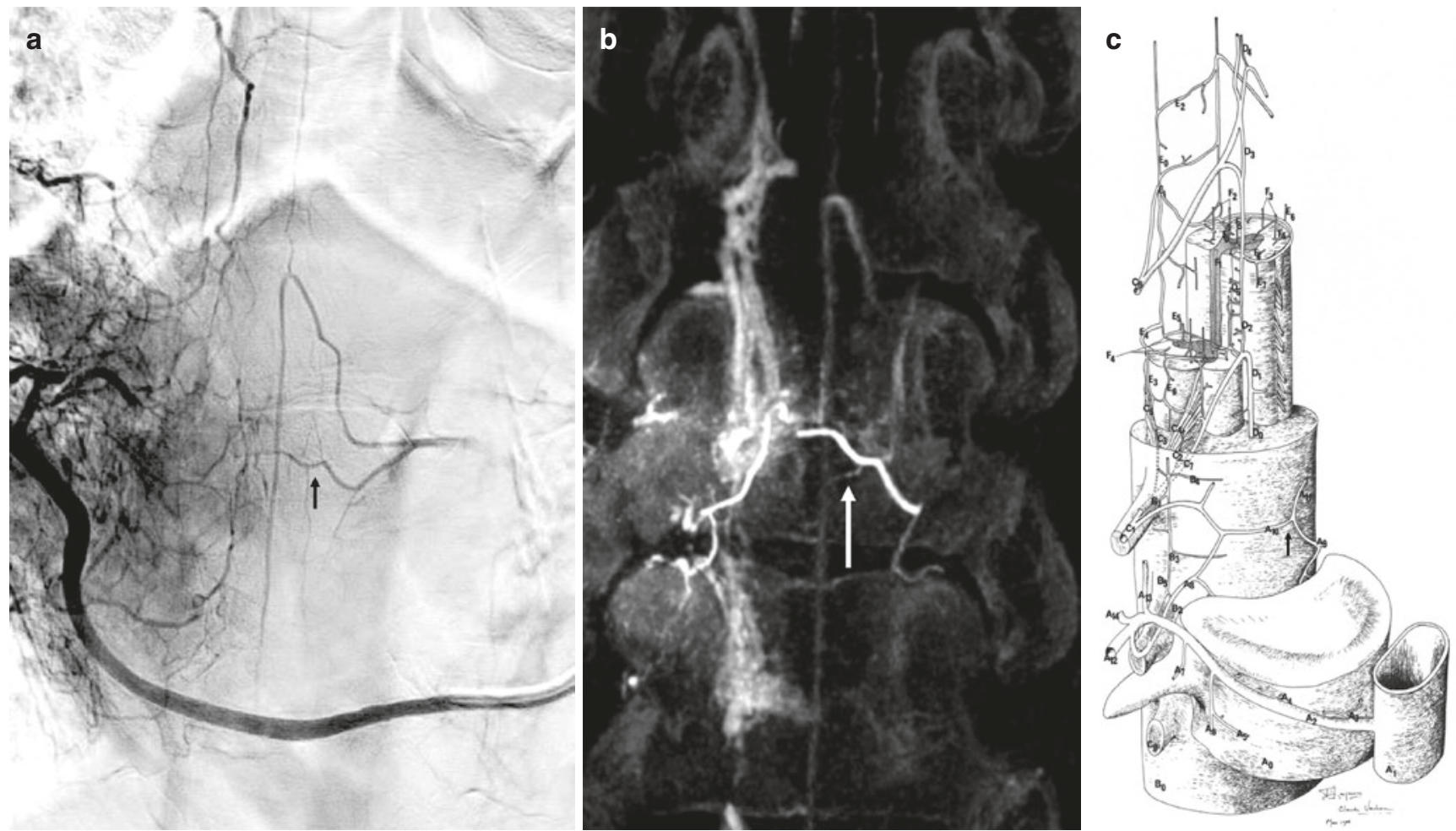

Fig. 4 (a) Right intercostal artery injection of DSA (AP view). (b) CBCT after complete elimination of the shunt. (c) Schematic representation of spine and spinal cord supply at the upper thoracic level. Note the contralateral DSB (arrow) is opacified through the anastomosis. The artery of Adamkiewicz is also visualized through this collateral supply 


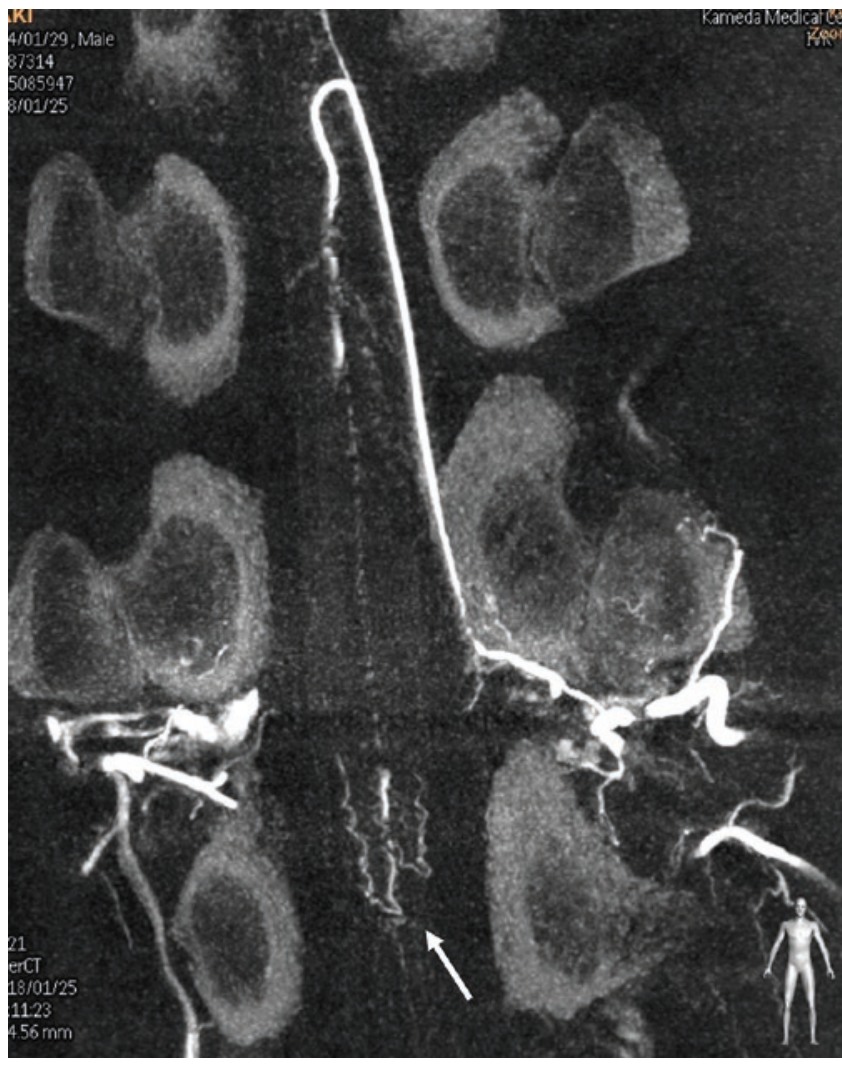

Fig. $5 \mathrm{CBCT}$ showed the great anterior radiculomedullary artery (Adamkiewicz artery) and the basket formation (arrow) at the level of conus medullaris

\section{Discussion}

In terms of digital images, spatial resolution refers to the number of pixels utilized in the construction of the image. The higher spatial resolution of medical images is essential in the management and giving the indication of therapeutic options for SDAVF [2, 3].

Recent advancements in imaging technology improved the performance and efficacies of MRI, CE-MRA, and MDCT in terms of the definition of the shunt point as well as the adjacent vasculatures. These imaging modalities are less invasive and are available in the outpatient clinic. However, the degree of definition and the sensitivities to the region of interest on these modalities are still inferior to the conventional DSA and CBCT with the use of invasive catheter angiography.

The discrimination between SDAVFs and spinal epidural fistulas (SEAVFs) is very important to the process of making a strategy of treatment and indicating the intervention. Kiyosue et al. reported on 168 patients with spinal dural and epidural arteriovenous fistulas from 31 centers in Japan [5]. Six readers analyzed the angioarchitecture. Approximately half of the epidural fistulas were incorrectly diagnosed as dural fistulas at the individual centers, highlighting the need

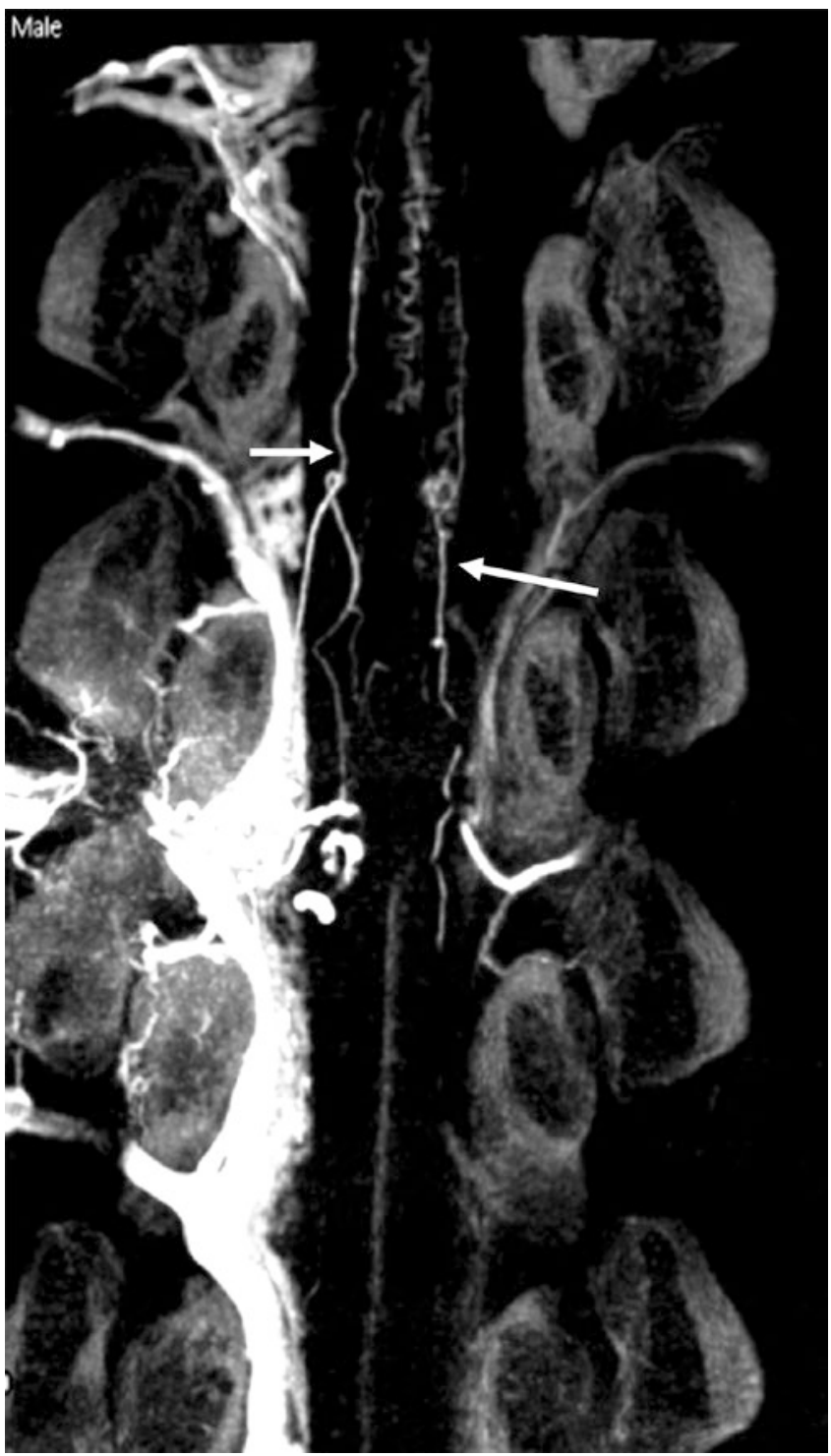

Fig. $6 \mathrm{CBCT}$ after complete elimination of the shunt. Note bilateral PSA were well-visualized on this plane (arrow)

to establish and publish distinguishing features. The shunt points of SDAVFs are more commonly located in the thoracic spine, whereas SEAVFs have a propensity to be in the lumbar spine and are associated with a history of spinal injury or surgery [5]. Both are more common in males and present with myelopathy. SDAVFs have their shunt point medial to the medial interpedicle line that indicates the estimated lateral margin of the thecal sac. They are supplied by meningeal branches of the radiculomeningeal artery. SEAVFs form epidural venous pouches located in the epidural space and shunt into the perimedullary vein, paravertebral veins, or both. They are supplied by epidural arteries, usually the DSB (dorsal somatic branch) $[2,3,5]$.

The distinction is also relevant for treatment. Whereas dural fistulas are favorable for open surgery and intradural 
division of the draining vein, epidural fistulas are better served by endovascular embolization $[6,7]$. Feeders to epidural fistulas also tend to be straight and more easily accessible using the endovascular route.

\section{Classification of SDAVFs Based on the Advanced Images in Terms of the Embryological Origin of the Dura Mater}

The higher definition images showed that typical SDAVFs had the shunt point on the lateral surface of the dura mater of the spinal canal, and it was more or less associated with the dura mater covering the nerve sleeve. The majority of SDAVFs are mainly supplied by meningeal branches from the radiculomeningeal artery. These meningeal branches anastomose vertically and drain into the single intradural vein, which typically forms horizontal $\mathrm{T}$ sign on a frontal view of spinal angiography and CBCT. It is generally thought that SDAVFs are located at the dura mater of the spinal nerve root sleeve and drain into the radiculomedullary vein. In normal anatomy, the drainage veins from the spinal cord, called radiculomedullary veins, run along the nerve root and penetrate the dura at the spinal nerve root sleeve. These radiculomedullary veins are found in $60 \%$ of the healthy population [8]. The remaining $40 \%$ show venous drainage of the spinal cord via the bridging vein, which runs apart from the nerve root and pierces the dura mater of the spinal cord to join the epidural venous plexus. SDAVFs can involve either the radiculomedullary vein or the bridging vein $[2,3,5]$. The dura mater at the level of the spinal cord are derived from the neural crest cell and consist of the single layer of dura propria, while the intracranial dura mater consists of dura propria and periosteal dura [9-12]. Thus, the characteristics of the dura mater of spinal cord are similar to the dura mater of crista galli (olfactory groove), falx cerebri, tentorium cerebelli, and falx cerebelli, because these dura maters consist only of the dura propria [13-16]. Additionally, those dura maters (dura propria) have the same origin of neural crest cell, while the convexity area of intracranial dura mater might derive from paraxial mesoderm, according to recent studies based on the immunostaining analysis of experimental model [10, 14, 17-19].

\section{Conclusions}

Three-dimensional angiography, particularly multiplanar reconstruction images with $\mathrm{CBCT}$, is quite useful for evaluating the microangioarchitecture of SDAVFs. This modality showed the exact localization of the shunt point. There are certain susceptibilities to the formation of the shunt on the lateral surface of the spinal canal, which is frequently independent from the nerve sleeves. The vulnerability of the dura mater might be associated with the fact that dura mater in the spinal canal consists only of the dura propria and derives from neural crest. SDAVFs and intracranial DAVFs located on the dura mater of the falco-tentorial, olfactory groove, falx cerebri, and tentorium cerebelli might belong to the same anatomical entity and they are composed only of the dura propria derived from neural crest.

Acknowledgments The author is grateful to Prof. T. Tsukahara, Prof. L. Regli, and Prof. M. Cenzato for suggesting the topic of this article.

Disclosure Statement: The author declares no conflicts of interest.

\section{References}

1. Jellema K (2003) Spinal dural arteriovenous fistulas: clinical features in 80 patients. J Neurol Neurosurg Psychiatry 74(10):1438-1440

2. Jeng Y, Chen DY-T, Hsu H-L, Huang Y-L, Chen C-J, Tseng Y-C (2015) Spinal dural arteriovenous fistula: imaging features and its mimics. Korean J Radiol 16(5):1119

3. Krings T, Geibprasert S (2009) Spinal dural arteriovenous fistulas. Am J Neuroradiol 30(4):639-648

4. Muralidharan R, Saladino A, Lanzino G, Atkinson JL, Rabinstein AA (2011) The clinical and radiological presentation of spinal dural arteriovenous fistula. Spine 36(25):E1641-E1647

5. Kiyosue H, Matsumaru Y, Niimi Y, Takai K, Ishiguro T, Hiramatsu M, Tatebayashi K, Takagi T, Yoshimura S (2017) Angiographic and clinical characteristics of thoracolumbar spinal epidural and dural arteriovenous fistulas. Stroke 48(12):3215-3222

6. Ropper AE, Gross BA, Du R (2012) Surgical treatment of type I spinal dural arteriovenous fistulas. Neurosurg Focus 32(5):E3

7. Yokoyama K, Okuda Y, Yamada M, Tanaka H, Ito Y, Yamashita M, Sugie A, Kawanishi M (2018) Microsurgery of spinal dural arteriovenous fistula using Indocyanine green video angiography: 2-dimensional operative video. Oper Neurosurg 0(0):2018

8. Lasjaunias P, Berenstein ATBK (2013) Spinal vein. Surgical Neuroangiography. Springer Science \& Business Media, Heidelberg. https://doi.org/10.1007/978-3-662-10172-8

9. Hurst RW, Bagley LJ, MSM D, Flamm ES (1999) Arteriovenous fistulas. Skull Base Surg 9(1):1-7

10. Jiang X, Iseki S, Maxson RE, Sucov HM, Morriss-Kay GM (2002) Tissue origins and interactions in the mammalian skull vault. Dev Biol 241(1):106-116

11. Morriss-Kay G, Ruberte E, Fukiishi Y (1993) Mammalian neural crest and neural crest derivatives. Ann Anat 175(6):501-507

12. Tanaka M (2016) Embryological consideration of dural arteriovenous fistulas. Neurol Med Chir 56(9):544-551

13. Adeeb N, Mortazavi MM, Tubbs RS, Cohen-Gadol AA (2012) The cranial dura mater: a review of its history, embryology, and anatomy. Childs Nerv Syst 28(6):827-837

14. MacK J, Squier W, Eastman JT et al (1993) Mammalian neural crest and neural crest derivatives. Interv Neuroradiol 14(6):501-507 
15. McBratney-Owen B, Iseki S, Bamforth SD, Olsen BR, MorrissKay GM (2008) Development and tissue origins of the mammalian cranial base. Dev Biol 322(1):121-132

16. Wu T, Chen G, Tian F, Liu H-X (2017) Contribution of cranial neural crest cells to mouse skull development. Int J Dev Biol 61(8-9):495-503

17. Le Douarin NM, Dupin E (2014) The neural crest, a fourth germ layer of the vertebrate embryo. In: Trainor PABT-NCC (ed) Neural crest cells. Elsevier, Boston, pp 3-26
18. Hirasawa T, Kuratani S (2015) Evolution of the vertebrate skeleton: morphology, embryology, and development. Zool Lett 1(1):2

19. O'Rahilly R, Müller F (2007) The development of the neural crest in the human. J Anat 211(3):335-351

Open Access This chapter is licensed under the terms of the Creative Commons Attribution 4.0 International License (http://creativecommons. org/licenses/by/4.0/), which permits use, sharing, adaptation, distribution and reproduction in any medium or format, as long as you give appropriate credit to the original author(s) and the source, provide a link to the Creative Commons license and indicate if changes were made.

The images or other third party material in this chapter are included in the chapter's Creative Commons license, unless indicated otherwise in a credit line to the material. If material is not included in the chapter's Creative Commons license and your intended use is not permitted by statutory regulation or exceeds the permitted use, you will need to obtain permission directly from the copyright holder. 